\title{
Integration Host Factor Is Essential for Biofilm Formation, Extracellular Enzyme, Zeamine Production, and Virulence in Dickeya zeae
}

\author{
Xuefeng Chen, Chengpeng Yu, Shuangchun Li, Xinwei Li, and Qiongguang Liu ${ }^{\dagger}$ \\ State Key Laboratory of Conservation and Utilization of Subtropical Agro-bioresources, Guangdong Province Key Laboratory of \\ Microbial Signals and Disease Control, College of Agriculture, South China Agricultural University, Guangzhou 510642, China \\ Accepted 14 September 2018.
}

\begin{abstract}
Dickeya zeae is a globally important pathogenic bacterium that infects many crops, including rice, maize, potato, and banana. Bacterial foot rot of rice caused by $D$. zeae is one of the most important bacterial diseases of rice in China and some Southeast Asian countries. To investigate the functions of integration host factor (IHF) in D. zeae, we generated knockout mutants of $i h f A$ and $i h f B$. Phenotypic assays showed that both the $\Delta i h f A$ and $\Delta i h f B$ strains had greatly reduced mobility, biofilm formation, extracellular protease, and pectinase activities, and toxin production compared with the wild-type strain. In addition, the mutants did not inhibit the germination of rice seeds, failed to cause soft rot in potatoes and a hypersensitive response in tobacco, and were avirulent in rice. Quantitative reverse-transcription polymerase chain reaction analysis demonstrated that IHF positively regulates the expression of $\mathrm{zmsA}, \mathrm{hrpN} / Y, \operatorname{pelA} / \mathrm{B} / \mathrm{C}, \mathrm{pehX}, \mathrm{celZ}, \mathrm{prtG}, \mathrm{fliC}$, and $D G C$ (diguanylate cyclase). Electrophoretic mobility shift assays further confirmed that IhfA binds to the promoter region of the $D G C$ gene and may alter the levels of a second bacterial messenger, c-di-GMP, to regulate the pathogenicity or other physiological functions of $D$. zeae. In summary, IHF is an important integrated regulator of pathogenicity in $D$. zeae.
\end{abstract}

Bacterial foot rot caused by Dickeya zeae (synonym Erwinia chrysanthemi pv. zeae) is one of the most serious diseases of rice. Since first being reported in Japan in the 1970s, outbreaks have occurred in the Philippines, India, Indonesia, Bangladesh, North Korea, and other southeast Asian countries, causing severe losses in rice production (Liu et al. 2013; Zhang et al. 2018). In addition to rice and maize, D. zeae also infects other economically important crops, such as potato and banana (Parkinson et al. 2009; Liu et al. 2015). Despite its importance, few studies have investigated the pathogenic mechanism of D. zeae. Quorum sensing is a widespread regulatory mechanism in plant-pathogenic bacteria and, in D. zeae, can modulate bacterial motility and the ability to form multicellular aggregates, ultimately affecting virulence (Hussain et al. 2008).

${ }^{\dagger}$ Corresponding author: Q. Liu; E-mail: qgliu @scau.edu.cn

Funding: This work was supported by the National Natural Science Foundation of China (31371903).

*The $\boldsymbol{e}$-Xtra logo stands for "electronic extra" and indicates that two supplementary figures are published online.

(c) 2019 The American Phytopathological Society
Recently, a novel polyamino-amide antibiotic, designated zeamine, with widespread antibacterial effect was identified in D. zeae (Wu et al. 2010). Further investigation indicated that zeamine, which is a phytotoxin, plays a key role in the pathogenicity of $D$. zeae in monocotyledonous plants (Cheng et al. 2013; Zhou et al. 2011). We have also previously shown that the two-component system HrpX/HrpY of D. zeae positively regulates motility, biofilm formation, and pathogenicity (Chen et al. 2014).

Integration host factor (IHF), which was first characterized as a $\lambda$-phage accessory protein involved in the site-specific recombination process (Miller and Friedman 1980), acts as a universal sequence-specific DNA-bending protein in many gram-negative bacteria (Dorman 2009; Muñoz et al. 2010). IHF is a small, heterodimeric protein of approximately $20 \mathrm{kDa}$ and is encoded by the genes ihfA and ihfB (Haluzi et al. 1991). Generally, a 13-bp specific consensus target sequence (WATCAANNNNTTR, W means A or T, R means A or G, N means any nucleotide) is recognized and bound by IHF, which then carries out its biological function (Hirano 2006). IHF proteins from Escherichia coli and other animal-pathogenic bacteria are involved in the transcriptional regulation of over 100 genes with different functions (Arfin et al. 2000; Mangan et al. 2006). For example, in Salmonella enterica serovar typhimurium LT2, IHF provides essential regulation of the enzymes involved in propionate catabolism, which are encoded by the prpBCDE operon (Palacios and Escalante-Semerena 2000). IHF binds to the promoter sequence of the $\operatorname{vir} B$ operon (the type IV secretion system), regulating the transcription of the downstream genes and thereby reducing the virulence of this pathogenic bacterium (Sieira et al. 2004). In Shigella flexneri, IHF positively regulates virulence gene expression through binding to multiple promoters, including those associated with virF, virB, and iscA (Porter and Dorman 1997). In addition, IHF plays a role in the regulation of virulence genes in Vibrio cholerae, including the inactivation of $i h f A$ and $i h f B$, and reducing the expression of the two main virulence genes, tcpA and $c t x$, so as to hinder production of the cholera toxin (Stonehouse, et al. 2008).

The requirement of IHF for virulence has also been described in plant-pathogenic bacteria. For example, IHF binds to the hrpLEcc promoter in Pectobactium carotovora subsp. carotovora (Chatterjee et al. 2002) and to the $h r p S$ promoter in Pantoea stewartii subsp. stewartii (Merighi et al. 2006), thereby modulating virulence by positively regulating genes involved in the type III secretion systems of these species (Chatterjee et al. 2002; Merighi et al. 2006). In addition, the presence of IHF greatly reduces bean toxin production by plant pathogen Pseudomonas syringae pv. phaseolicola (Arvizu-Gómez et al. 
2011). Interestingly, while IHF is essential for RpoN-dependent hrpL expression in Erwinia amylovora, it can also control bacterial motility by positively regulating $r s m B$ sRNA (Lee and Zhao 2016) and positively regulates hrpS expression through directly binding the $h r p X$ promoter and positively regulating $h r p X / h r p Y$ expression (Lee and Zhao 2018). However, little is known about the role of IHF in $D$. zeae.

In this study, D. zeae $\Delta i h f A$ and $\Delta i h f B$ deletion mutant strains were generated and were subjected to phenotypic and gene expression analyses in comparison with the wild-type strain for understanding the role of IHF in the regulatory cascade controlling D. zeae pathogenesis.

\section{RESULTS}

Mutations in ihfA and ihfB significantly affect the bacterial growth.

To characterize the function of IHF in $D$. zeae, we successfully constructed single knockout mutant strains $\triangle i h f A$ and $\Delta i h f B$ along with their respective complementation strains, R- $\Delta i h f A$ and R- $\Delta i h f B$ (Supplementary Fig. S1). To determine whether the IHF-encoding genes affect the growth and proliferation of D. zeae, the growth of the wild-type, mutant, and complementation strains was compared in Luria Bertani (LB) medium. Compared with the wild type, both $\Delta i h f A$ and $\Delta i h f B$ initially grew much more slowly; however, both mutant strains reached cell densities similar to that of the wild type at $24 \mathrm{~h}$ postinoculation. Complementation mutant strains R- $\Delta i h f A$ and R$\triangle i h f B$ showed similar growth patterns to the wild type (Fig. 1).

\section{IHF positively regulates motility and biofilm formation in $D$. zeae.}

Equal amounts of D. zeae wild-type, mutant, and complementation strains were transferred onto semisolid agar plates and were cultured for $24 \mathrm{~h}$. Mutant strains $\triangle i h f A$ and $\triangle i h f B$ exhibited decreased circular movement, with decreases in colony diameter

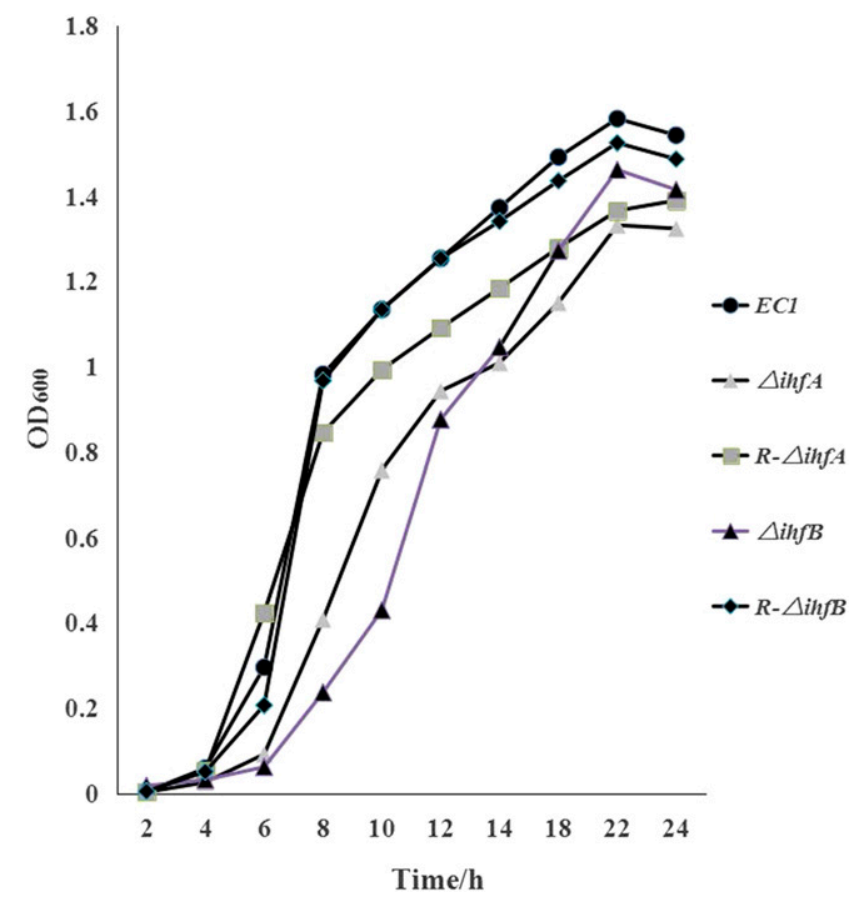

Fig. 1. Growth curves of Dickeya zeae wild-type strain EC1, integration host factor $(I H F)$ mutants, $\triangle i h f A$ and $\triangle i h f B$, and their complementation strains, R- $\Delta i h f A$ and R- $\Delta i h f B$. The growth (optical density at $600 \mathrm{~nm}$ $\left.\left[\mathrm{OD}_{600}\right]\right)$ of each strain, in Luria Bertani medium at $30^{\circ} \mathrm{C}$, was measured at every $2 \mathrm{~h}$. Datapoints represent the means of three replicates. compared with the wild type of 37.5 and $71.9 \%$, respectively. The complementation strains R- $\Delta i h f A$ and R- $\Delta i h f B$ produced similar results to the wild-type strain EC1 (Fig. 2).

Biofilms are bacterial communities attached to a surface. Life in these communities provides protection from deleterious conditions. Therefore, biofilm formation is considered important for the disease cycle of bacterial pathogens of both animals and plants. Both mutant strains showed a significant decrease in biofilm formation in glass tubes compared with the wild-type and complementation strains (Fig. 3).

\section{IHF positively regulates the activities}

of extracellular enzymes and toxin in D. zeae.

In many phytobacteria, proteases, cellulases, and pectinases are pathogenic factors. The activities of these extracellular enzymes were, therefore, investigated in the $D$. zeae wild-type,

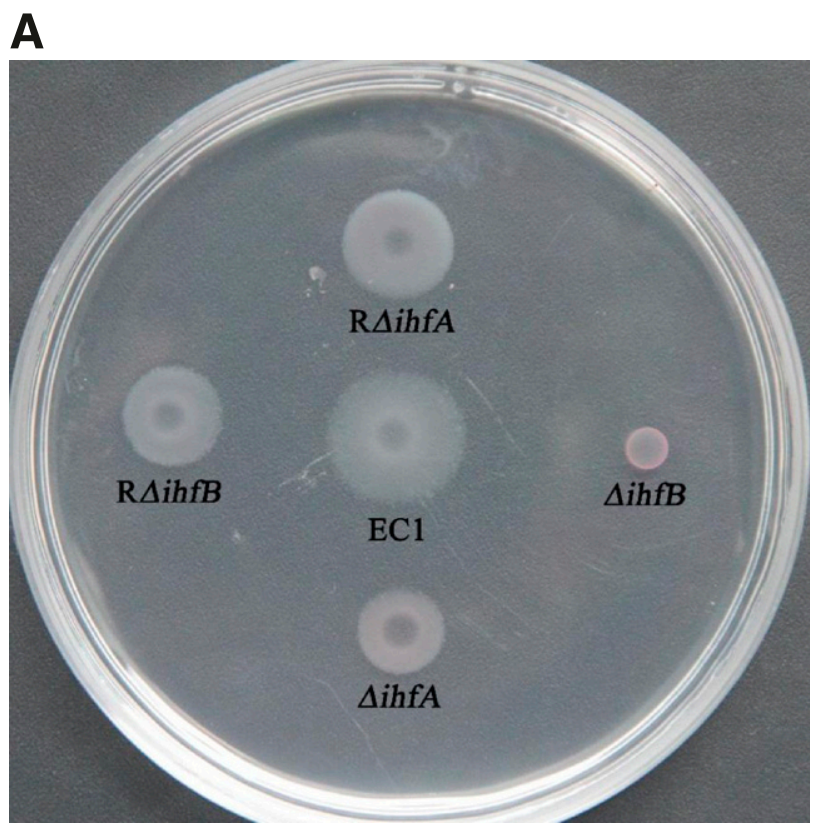

B

\section{5}

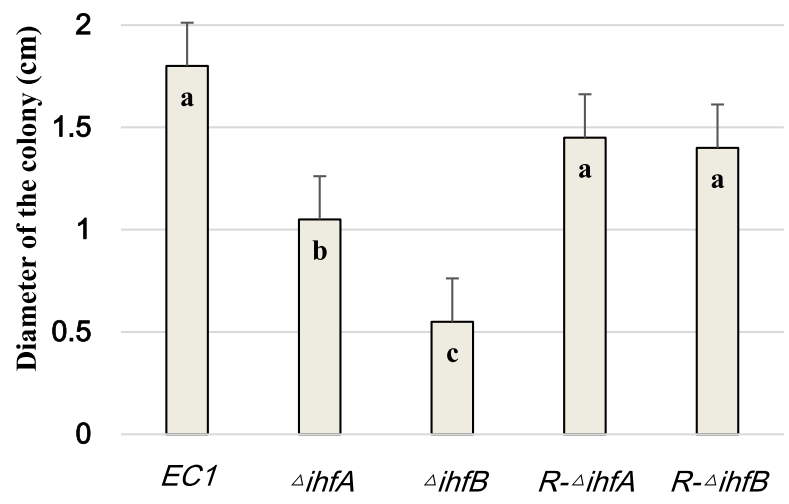

Fig. 2. Motility of Dickeya zeae wild-type strain EC1, integration host factor $(I H F)$ mutants, $\triangle i h f A$ and $\triangle i h f B$, and their complementation strains, R- $\Delta i h f A$ and R- $\Delta i h f B$. A, Two microliters of the bacterial suspensions (optical density at $600 \mathrm{~nm}\left[\mathrm{OD}_{600}\right]=1.5$ ) were inoculated at the center of the motility plate with semisolid medium and were incubated for $24 \mathrm{~h}$ at $30^{\circ} \mathrm{C}$ to assess the movement of these strains on the motility plate. $\mathbf{B}$, The diameters of the growth circle around the inoculation site were measured. Values are means of three replicates and the error bars are standard deviation. Statistical analysis was performed on all data together and significantly different values (analysis of variance $P<0.05$ ) are indicated by different letters. 
mutant, and complementation strains. The results showed that, compared with the wild type, the protease activity of $\triangle i h f A$ and $\Delta i h f B$ was decreased by 95 and $82 \%$, respectively (Fig. 4A and E), while the pectinase activity of the two strains was also decreased by 62 and $65 \%$, respectively. (Fig. 4B and E). However, no significant decreases in cellulase activity were observed for the two mutant strains compared with the wildtype (Fig. 4C and E), indicating that IHF positively regulates the activities of proteases and pectinases but not that of cellulases in D. zeae.

The toxins produced by wild-type $D$. zeae can inhibit the growth of E. coli on LB plates (Zhou et al. 2011). Therefore, tested strains were compared for bactericidal activity against $E$. coli on LB medium. Neither $\Delta i h f A$ nor $\Delta i h f B$ produced zones of inhibition on plates spread with $E$. coli, while the complemented strains R- $\Delta i h f A$ and R- $\Delta i h f B$ produced inhibition zones similar to those of the wild-type strain (Fig. 4D and E), suggesting that IHF is involved in toxin production in D. zeae.

\section{IHF mutants lost the ability}

\section{to inhibit rice seed germination.}

Virulent D. zeae strains strongly inhibit the germination of rice seeds (Zhou et al. 2011). Comparison of the effects of the wild-type, mutant, and complementation mutant strains on rice seed germination showed that there was no significant difference between the mutant strains and the blank control in germination. In contrast, the complementation strains showed strong inhibition of rice seed germination that was comparable to that of the wild-type strain (Fig. 5). This indicated that deletion of the IHF-encoding genes reduced the ability of the bacterium to inhibit rice seed germination.

\section{Deletion of IHF abolishes virulence in potato and rice} and the hypersensitive response (HR) in tobacco.

To characterize the role of IHF in the virulence of D. zeae, the wild-type, mutant, and complementation mutant strains were inoculated onto potato, rice, and tobacco plants, which were then monitored for signs of disease. At $24 \mathrm{~h}$ postinoculation, the slices of potato inoculated with the wild-type, R- $\Delta i h f A$, or R$\triangle i h f B$ strains showed signs of severe soft rot, while the potato slices inoculated with mutant strains $\Delta i h f A$ or $\Delta i h f B$ had very few symptoms of soft rot (Fig. 6A). This indicated that IHF is required for the development of $D$. zeae-induced soft rot in potatoes.

Symptoms of soft rot, including curling and wilt of interior leaves and watery brown spots on the leaf sheath at the base of the stem, were observed in rice seedlings inoculated with the wild-type or complementation strains at $48 \mathrm{~h}$ postinoculation. At 7 days postinoculation, the stem bases of rice seedlings inoculated with the wild-type or complemention mutant strains turned black and rotten, giving off a putrid smell (Fig. 6B). However, no symptoms appeared in the rice seedlings inoculated with the mutants $\triangle i h f A$ and $\Delta i h f B$ (Fig. 6B). This implies that IHF is essential for D. zeae to cause foot rot on rice seedlings.

At $24 \mathrm{~h}$ postinoculation, no signs of a HR were present on tobacco leaves inoculated with mutant strains $\triangle i h f A$ or $\Delta i h f B$, while a HR was apparent on tobacco leaves inoculated with the wild-type, R- $\Delta i h f A$, or R- $\Delta i h f B$ strains (Fig. 6C). This result confirmed that IHF regulates the Hrp system in D. zeae.

\section{IHF positively regulates the expression}

of some virulent genes in $D$. zeae.

To verify the downstream genes regulated by IHF, the expression of several target genes, including zms $A$ (encodes a novel multimodular polyketide synthase forzeamine toxin), $h r p N$ and $h r p Y$ (Hrp system), pectate lyase genes (pelA, pelB, pelC), polygalacturonases (pehX), celY and celZ (cellulase), $\operatorname{prt} G$ (serralysin $\mathrm{G}$ ), fliC (a regulatory gene in flagellum system), and $D G C$ (diguanylate cyclase) in the D. zeae wild-type, $\triangle i h f A$, and $\triangle i h f B$ strains was compared, using quantitative reverse-transcription polymerase chain reaction (qRT-PCR) analysis. The results showed that the expression of zmsA, hrpN, $h r p Y$, pelA, pelB, pelC, pehX, celZ, prtG, fliC, and DGC was significantly decreased in the mutant strains compared with that in wild-type strain EC1 (Fig. 7). Interestingly, the decrease in gene expression was more noticeable in $\triangle i h f B$ than in $\Delta i h f A$. However, the expression of $c e l Y$ was significantly higher in $\triangle i h f A$. This indicates that IHF positively regulated the expression of several virulence genes in D. zeae.

\section{IhfA binds to the DGC promoter.}

IHF recognizes a specific asymmetric DNA sequence, WCARNWNNTTR, which is conserved in the IHF $\alpha$-subunitencoding gene ihfA. After binding to this sequence, IHF causes the DNA to bend at an angle of up to $180^{\circ}$ at the $5^{\prime}$ terminal region of the binding site ( $\left.5^{\prime}-\mathrm{WWWCAR}-3^{\prime}\right)$ (Hirano 2006; Wagner 2000). To investigate this binding, IhfA was expressed and purified (Supplementary Fig. S2). Cyclic di-GMP is a second bacterial messenger that is synthesized from two molecules of GTP by the action DGC and is then hydrolyzed by specific c-di-GMP phosphodiesterases (PDE) (Schirmer and Jenal 2009). DGC can regulate virulence in some bacterial plant pathogens by modulating the intracellular c-di-GMP levels (Chatterjee et al. 2010; Edmunds et al. 2013; Su et al. 2016). Analysis of DGC promoter sequences identified a putative IHF-binding site (TTATCAGTTGATTA) in the promoter region (within the -214 bp box) upstream of the DGC open reading frame (Fig. 8A). To verify whether IhfA binds to this specific sequence in the DGC promoter, an electrophoretic mobility shift assay (EMSA) was

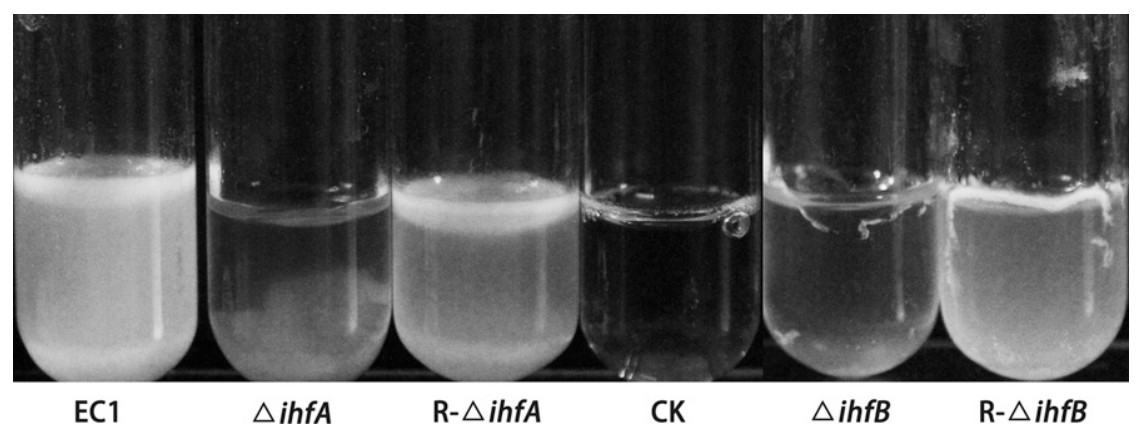

Fig. 3. Biofilm formation of Dickeya zeae wild-type strain EC1, $\Delta i h f A$, and $\Delta i h f B$, and their complementation strains R- $\Delta i h f A$ and R- $\Delta i h f B$. A $10-\mu 1$ aliquot of bacterial cell culture (optical density at $600 \mathrm{~nm}=0.5$ ) was inoculated into tubes containing SONG medium (per liter: $20 \mathrm{~g}$ of tryptone, $5 \mathrm{~g}$ of yeast extract, $5 \mathrm{~g}$ of $\mathrm{NaCl}, 2.4 \mathrm{~g}$ of $\mathrm{MgSO}_{4} \cdot 7 \mathrm{H}_{2} \mathrm{O}, 0.186 \mathrm{~g}$ of $\mathrm{KCl}, 50 \mathrm{ml}$ of $40 \%$ glycerin) and was incubated for $72 \mathrm{~h}$ at $28^{\circ} \mathrm{C}$. $\Delta$ ihfA and $\Delta$ ihfB showed a significant decrease in biofilm formation in glass tubes compared with wide-type strain EC1 and the complemented strains. 
performed using a probe targeting this region. The results demonstrated that IhfA could bind to the DGC promoter (Fig. 8B).

\section{DISCUSSION}

Virulence factors and secondary metabolites produced by plantpathogenic bacteria are normally controlled via a strict process that responds to multiple environmental cues. IHF is a global regulatory factor in some animal- and plant-pathogenic bacteria (Chatterjee et al. 2002; Lee and Zhao 2016; Mangan et al. 2006; Merighi et al. 2006; Sieira et al. 2004; Stonehouse et al. 2008), in which it regulates many biological functions, including virulence (ArvizuGómez et al. 2011; Lee and Zhao 2016, 2018; Mangan et al. 2006; Stonehouse et al. 2008). However, little is known about the IHF

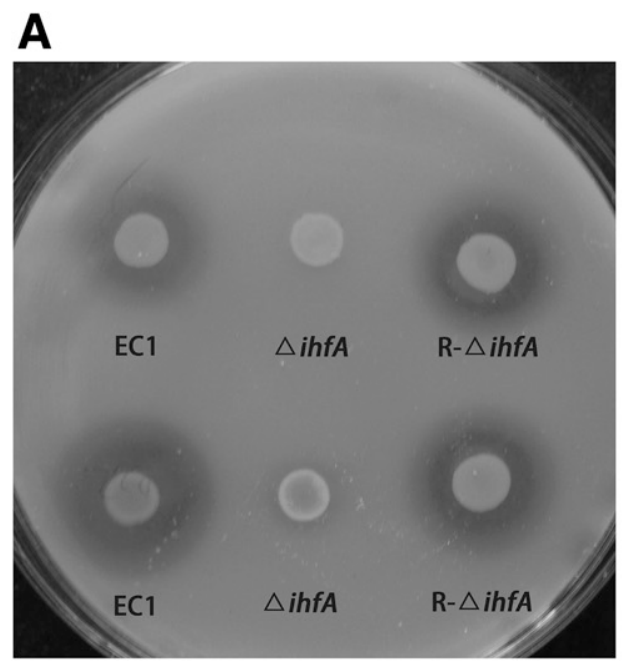

D

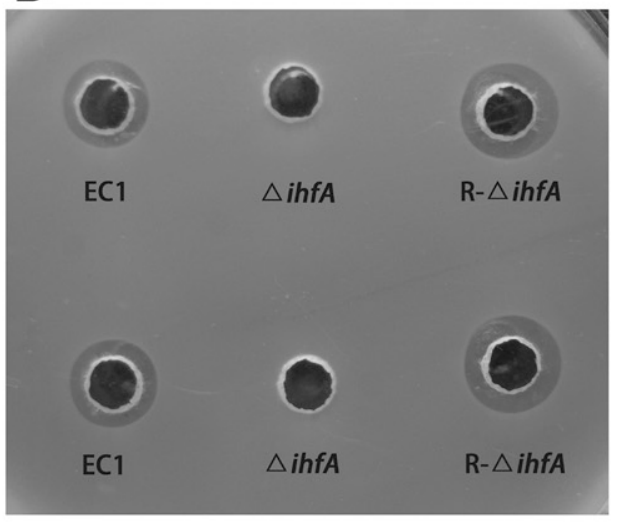

B

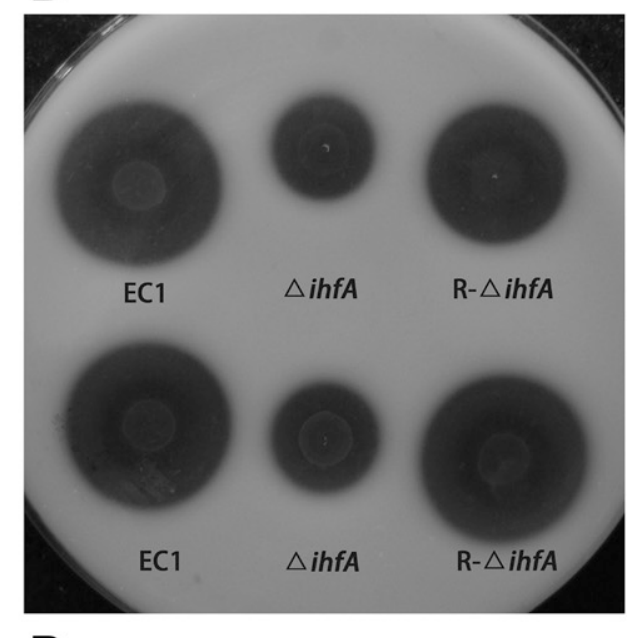

C

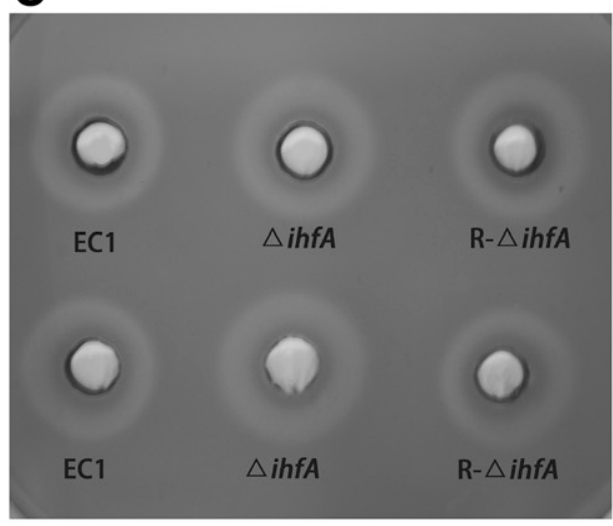

D

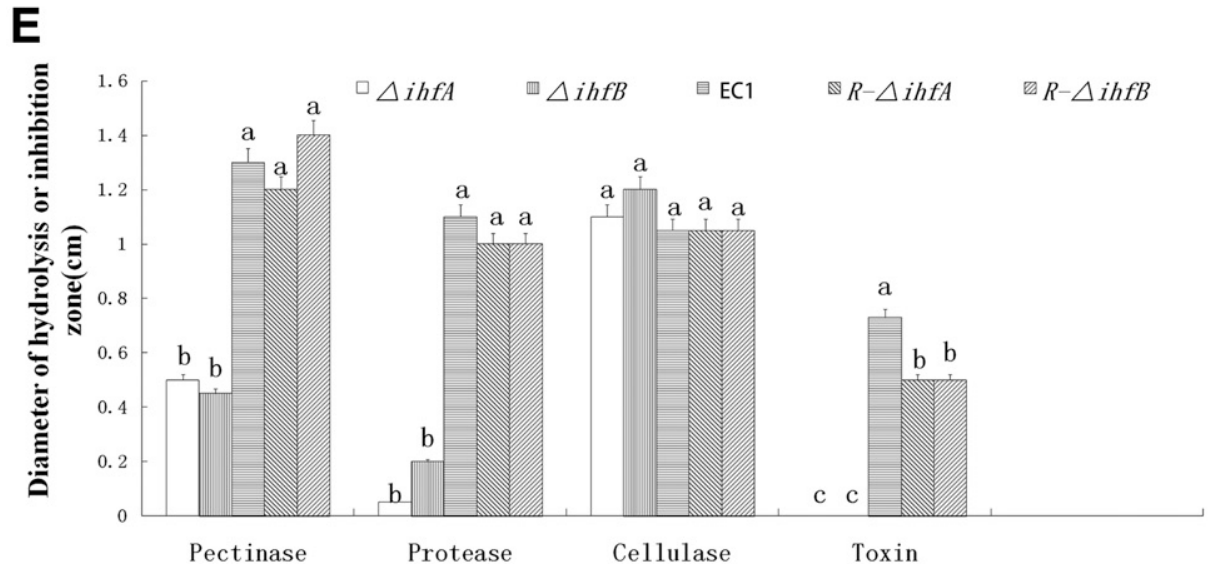

Fig. 4. Determination of extracellular enzymes and toxin of Dickeya zeae wild-type strain EC1, $\Delta i h f A$, and $\Delta i h f B$, and their complementation strains, R- $\Delta i h f A$ and $\mathrm{R}-\Delta i h f B$. A, Protease assay. $2 \mu \mathrm{l}$ of the bacterial suspensions were inoculated on the Luria Bertani plate with $2 \%$ defatted milk and were cultivated for $24 \mathrm{~h}$ at $30^{\circ} \mathrm{C}$, to observe the hydrolysis zone around the colony. B, Pectinase assay. Bacterial suspensions $(2 \mu \mathrm{l})$ were inoculated on the pectinase test plate with $1 \%$ polygalacturonic acid and were cultivated for $24 \mathrm{~h}$ at $30^{\circ} \mathrm{C}$, then, a 1-mol/liter $\mathrm{HCl}$ solution was poured into the plate and the transparent zone was observed. $\mathbf{C}$, Cellulase assay. Bacterial supernatants $\left(50 \mu \mathrm{l}\right.$ ) were added into the hole of a carboxymethyl ethyl cellulose plate and were incubated for $24 \mathrm{~h}$ at $30^{\circ} \mathrm{C}$. The plate was then stained with $0.1 \%$ (wt/vol) Congo red for $30 \mathrm{~min}$, was washed with $1 \mathrm{M} \mathrm{NaCl}$, and the size of hydrolysis zone around the hole was observed. D, Toxin assay. Bacterial supernatants (50) $\mu \mathrm{l}$ were added into the hole of an Escherichia coli plate and were incubated for $24 \mathrm{~h}$ at $30^{\circ} \mathrm{C}$, to observe the inhibition zone. E, A bar graph showing the measurement of diameters of hydrolysis zones observed in $\mathrm{A}$ and $\mathrm{C}$ or inhibition zone in $\mathrm{D}$. The values are means of three replicates and the error bars are standard deviation Statistical analysis was performed on each group of data and significantly different values (analysis of variance $P<0.05$ ) are indicated by different letters. 
proteins in the important plant pathogen $D$. zeae. In this study, we demonstrated that IHF is essential for zeamine toxin production and virulence of $D$. zeae and controls swimming motility, biofilm formation, and the expression of extracellular enzymes.

Bacterial motility is particularly important in the early stages of host invasion (Shen et al. 2001). In animal-pathogenic species Yersinia enterocolitica and Shewanella oneidensis, bacterial motility and biofilm formation are closely related to pathogenicity (Liang et al. 2010; Kim et al. 2008). This has also proven to be the case in plant-pathogenic bacteria, including $X$. campestris pv. campestris (Dow et al. 2003). In the current study, both the $\Delta i h f A$ and $\Delta i h f B$ mutant strains showed a significant reduction in motility and biofilm formation compared with the wild-type strain EC1. Expression analyses showed that the expression of important flagellum gene fliC was significantly decreased in the IHF mutants. Bacterial flagella are known to play important roles in swimming motility, biofilm formation, and virulence (Chua et al. 2003). Therefore, we suspect that bacterial motility plays an essential role in the initial stages of D. zeae infection and indicates that IHF positively regulates bacterial motility and biofilm formation.

Extracellular enzymes have been well-characterized in Pectobacterium and Dickeya species because of their essential roles in the development of soft rot symptoms (Matsumoto et al. 2003). Some pathogenic bacteria produce cell walldegrading enzymes, such as pectinases, polygalacturonases, proteases, and cellulases, as dominant virulent factors. These enzymes help to acquire nutrients by breaking down the cell walls of plants and aid in pathogenicity (Eriksson et al. 1998; Reverchon et al. 2016). In our study, compared with the wildtype, protease activity of the IHF mutants decreased by $>82 \%$, while the activity of pectinases was decreased by $62 \%$. qRTPCR analysis showed that the expressions of pelA, pelB, pelC, pehX, and $\operatorname{prt} G$ was significantly reduced in strains $\triangle i h f A$ and $\Delta i h f B$, which agrees with the results of the phenotypic assays. It is interesting to note that, although we did not observe any significant differences in cellulase activity between the mutant and the wild-type strains in the plate assays, qRT-PCR analysis showed a significant decrease in the expression of celY and celZ in $\triangle i h f B$ and a significant increase in celY expression in $\triangle i h f A$ compared with the wild-type strain. Cellulases are enzyme complexes containing several different enzymatic subunits, including endocellulases, exocellulases, cellobiases, oxidative cellulases, and cellulose phosphorylases. As we only examined two of the genes involved in these complexes (celY and celZ), it is perhaps not surprising that the cellulase enzyme activity shown by the plate test was not reflected in the changes in expression of the limited number of genes examined. Further, changes in gene expression do not necessarily directly translate to higher or lower enzyme activity.

In some pathogenic bacteria, including Vibrio cholerae (Stonehouse et al. 2008), Pseudomonas syringae pv. phaseolicola (Arvizu-Gómez et al. 2011), and D. zeae (Zhou et al. 2011), toxins are a vital virulence factor. In Pseudomonas syringae pv. phaseolicola, IHF binds to the promoter region of the phtD operon, which is involved in phaseolotoxin synthesis (Arvizu-Gómez et al. 2011). Zeamine toxin is a key virulence factor of $D$. zeae in both rice seeds and plants (Zhou et al. 2011). Our results indicated that $\triangle i h f A$ and $\triangle i h f B$ produced little zeamine toxin and showed a significantly decreased inhibitory effect on rice seed germination and reduced development of soft rot in potato and rice plants. Further qRT-PCR analysis verified that the expression of $z m s A$, the zeamine toxin synthesis gene in D. zeae (Zhou et al. 2011), was four times lower in the $\triangle i h f A$ and $\triangle i h f B$ mutants than in the wild type, accounting for the reduced toxin activities of the mutant strains.
Therefore, we propose that IHF is required for the production of zeamine toxin in $D$. zeae.

Type 3 secretion systems (T3SS), encoded by the hrp gene cluster, are essential virulence factors in many plantpathogenic bacteria and play a role in eliciting the HR in plants (Deane et al. 2010; Lara-Tejero et al. 2011; Yap et al. 2005). Our results indicated that IHF mutants $\Delta i h f A$ and $\Delta i h f B$ did not cause a HR in tobacco, and our qRT-PCR analysis revealed significant decreases in the expression of $h r p N$ and $h r p Y$ (the important gene in Hrp cluster) in the IHF mutants. In Erwinia amylovora, the regulatory protein $\mathrm{HrpY}$ forms a complex with HrpS that binds to the promoter region of $h r p L$, thereby inducing gene expression (Wei et al. 2000). However, recent studies have shown that HrpY binds to the promoter of HrpS to regulate HrpS expression (Lee and Zhao 2018) Previously, we found that the HrpX/HrpY twocomponent system of $D$. zeae positively regulates bacterial motility, biofilm formation, and the expression of downstream hrp genes and, also, plays a role in the early stages of infection of rice plants (Chen et al. 2014). Taken together, these results imply that IHF may regulate the T3SS of D. zeae.

Cyclic di-GMP is a second messenger for many bacteria, but its synthesis and degradation require two key enzymes, DGC and PDE (Schirmer and Jenal 2009). Extensive research has delineated the important role of bacterial c-di-GMP in regulating biofilm formation and the expression of virulence genes (Chin et al. 2010; Dahlstrom et al. 2016; Jenal et al. 2017; Römling et al. 2013; Ryan 2013). In Dickeya dadantii, two phosphodiesterases, EcpB and EcpC, which are involved in the synthesis and degradation of c-di-GMP, could adjust and positively control the expression of the T3SS, thereby influencing cellular behaviors as well as virulence. However, deletion of one or both $е c p B$ and $е c p C$ enhanced biofilm formation but repressed swimming and swarming motility and reduced pectate lyase production (Yi et al. 2010). Our results showed that IHF positively regulates the expression of DGC, a key enzyme
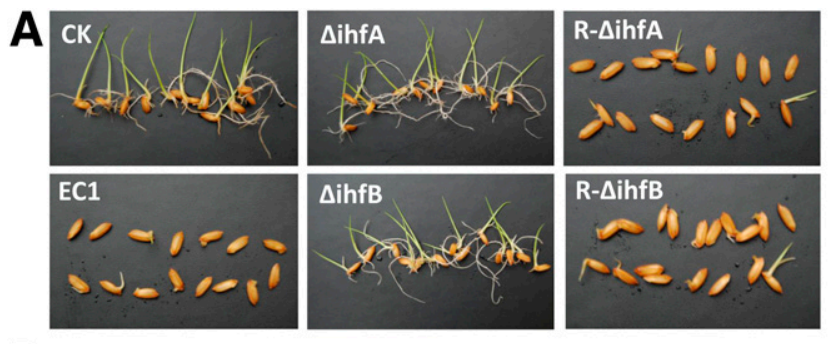

B

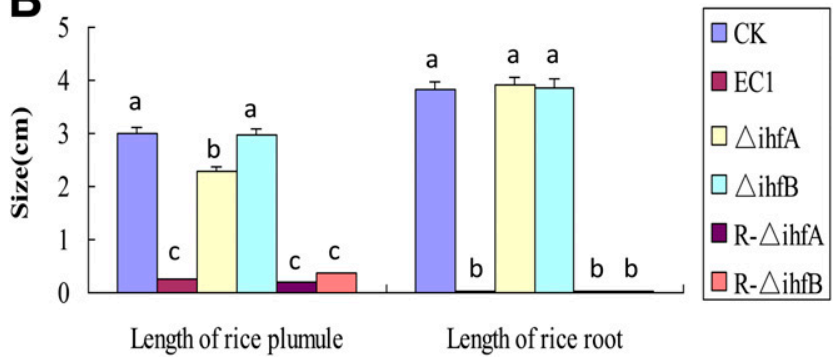

Fig. 5. Effects of Dickeya zeae wild-type strain EC1, $\Delta i h f A$, and $\Delta i h f B$, and their complementation strains, R- $\Delta i h f A$ and $\mathrm{R}-\Delta i h f B$, on the rice seed germination. A, Rice seeds were immersed in bacterial supernatants for $5 \mathrm{~h}$, were washed three times with sterilized water, and were then incubated for 4 days at $30^{\circ} \mathrm{C}$, to observe the germination of rice seeds. B, The length of the rice plumule and root were measured. Luria Bertani medium was used as a blank control (CK). The values are means of three replicates and the error bars are standard deviation. Statistical analysis was performed on each group of data and significantly different values (analysis of variance $P<$ $0.05)$ are indicated by different letters. 
in the synthesis of cyclic di-GMP, and is positively associated with motility, biofilm formation, toxin production, and enzyme activity. These findings agree with a previous study that showed that deletion of DGC protein CgsA was associated with a reduction of virulence in Xylella fastidiosa (Chatterjee et al. 2010). However, in Xanthomonas oryzae pv. oryzae, DgcA, a DGC, negatively affected virulence, exopolysaccharides production, bacterial autoaggregation, and motility, but positively affected biofilm formation via modulation of the in tracellular c-di-GMP levels ( $\mathrm{Su}$ et al. 2016). These findings indicate that the roles and functions of DGC proteins can vary in different plant-pathogenic bacteria. In addition, bacterial c-di-GMP levels are affected by the key enzymes DGC and PDE. Further investigation is needed to determine the role of

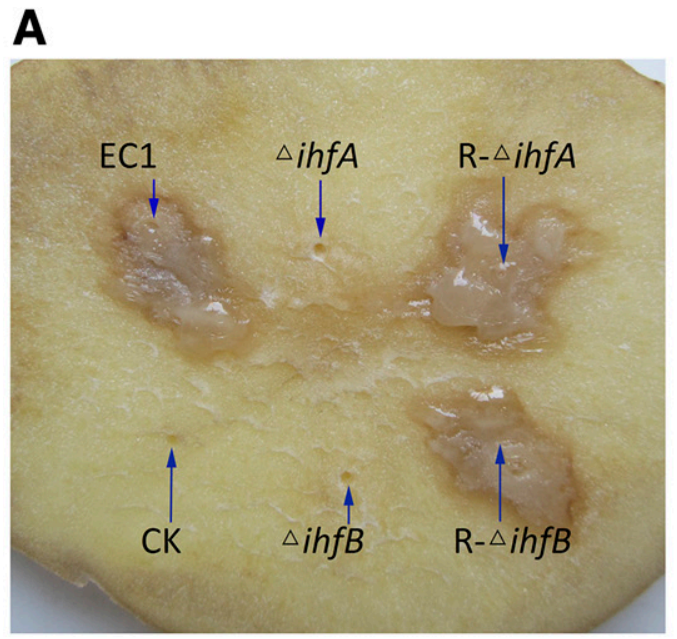

B

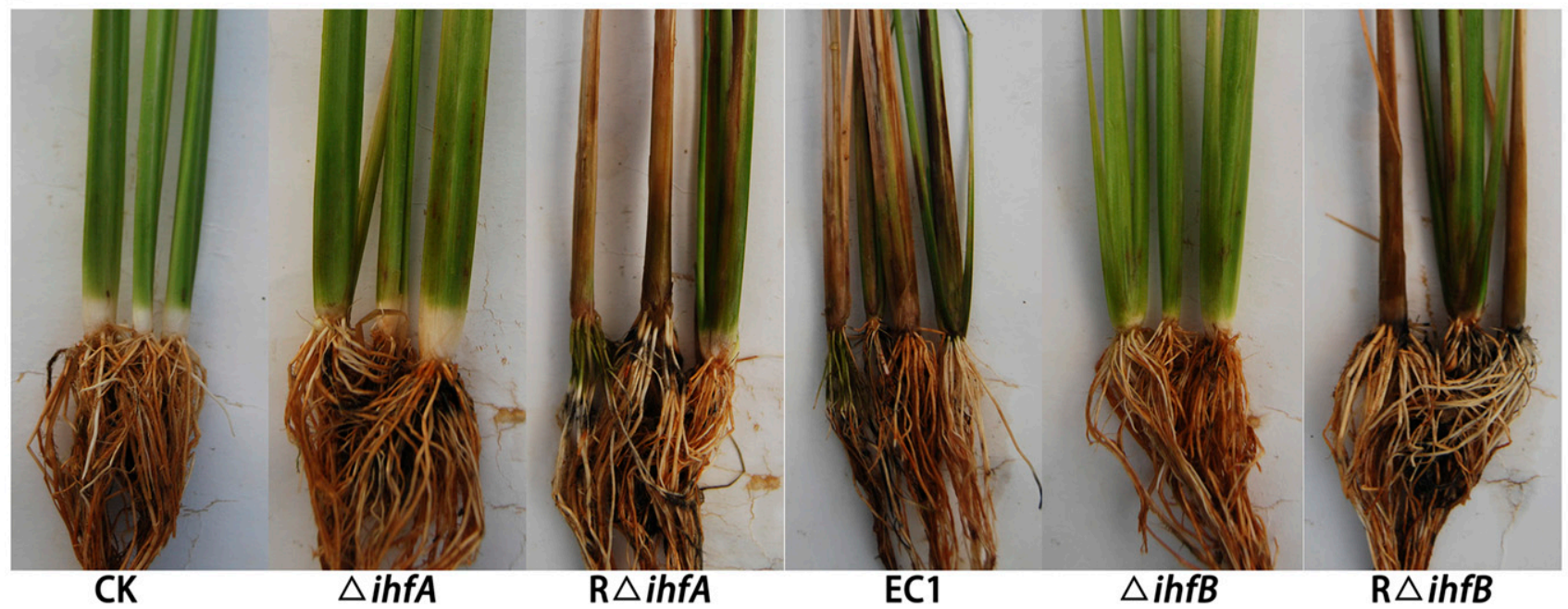

C

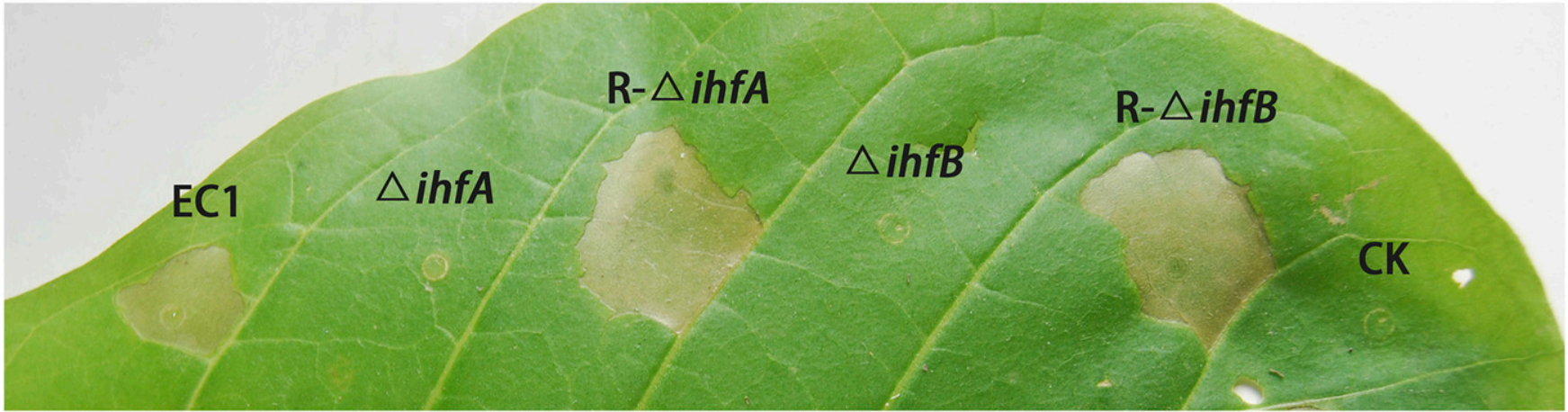

Fig. 6. Virulence assay of Dickeya zeae wild-type strain EC1, $\Delta i h f A, \Delta i h f B$, and their complementation strains, R- $\Delta i h f A$ and R- $\Delta i h f B$, on potato, rice, and tobacco. A, Symptoms of soft rot in potato. Healthy potato tube pieces were inoculated with $2 \mu \mathrm{l}$ of bacterial suspensions (optical density at $600 \mathrm{~nm}\left[\mathrm{OD}_{600}\right]=$ $0.5)$ and were incubated at $30^{\circ} \mathrm{C}$ for $24 \mathrm{~h}$, to observe soft rot on the potato piece. The arrows indicate inoculation positions. B, Symptoms of soft rot on rice plants. The bacterial suspensions $\left(\mathrm{OD}_{600}=0.5\right)$ were injected into the base of rice seedlings, and the curling and wilt of interior leaves, watery brown spots in the leaf sheath at the stem base, were observed 2 days later. $\mathbf{C}$, Hypersensitive response on tobacco leaves. Bacterial suspensions $\left(\mathrm{OD}_{600}=0.5\right)$ were injected into the tobacco leaves and, $24 \mathrm{~h}$ later, the hypersensitive response on the inoculation sites was observed. 
c-di-GMP in D. zeae, although the present results show that IhfA binds to the promoter region of $D G C$ in $D$. zeae, thereby controlling the expression of $D G C$.

Bacterial genomes are likely to contain multiple target gene promoters containing the conserved IHF binding sequence. For example, IHF binds to the promoter sequence of the virB operon (the type IV secretion system) in Brucella abortus to regulate the transcription of downstream genes and alter bacterial virulence (Sieira et al. 2004). In Shigella flexneri, IHF positively regulates virulence gene expression by binding to multiple promoters, including those associated with virF, virB, and icsA (Porter and Dorman 1997). In other plant pathogens, IHF binds to the promoters of hrpL in Pectobacterium carotovorum subsp. carotovorum (Chatterjee et al. 2002), hrpS in Pantoea stewartii subsp. stewartii (Merighi et al. 2006), and the phtD operon, which is involved in phaseolotoxin synthesis, in Pseudomonas syringae pv. phaseolicola (Arvizu-Gómez et al. 2011). Our results showed that IhfA binds to the promoter region of the $D G C$ operon in D. zeae, which is involved in the synthesis of c-di-GMP, to alter bacterial behaviors. These results suggest that IHF is involved in the regulation of many different target genes in different pathogenic bacteria.

In summary, we demonstrated that IhfA binds to the promoter region of $D G C$ in $D$. zeae, which may affect the concentration of the second bacterial messenger, c-di-GMP, thereby influencing bacterial motility, biofilm formation, and the production of extracellular enzymes and toxins. Further, deletion of the IHF-encoding genes ihfA and ihfB resulted in reduced expression of several virulence factors, including the T3SS and its virulence effector proteins. Therefore, we suggest that IHF is an important integrated regulator of pathogenicity in D. zeae.

\section{MATERIALS AND METHODS}

Bacterial strains, plasmids, and growth conditions.

The bacterial strains and the plasmids used in this study are outlined in Table 1 . All bacterial strains of D. zeae were grown on minimal medium (MM) (per liter: $10.5 \mathrm{~g}$ of $\mathrm{K}_{2} \mathrm{HPO}_{4}, 4.5 \mathrm{~g}$ of $\mathrm{KH}_{2} \mathrm{PO}_{4}, 2.0 \mathrm{~g}$ of mannitol, $2.0 \mathrm{~g}$ of $\left(\mathrm{NH}_{4}\right)_{2} \mathrm{SO}_{4}, 0.2 \mathrm{~g}$ of $\mathrm{MgSO}_{4} \cdot 7 \mathrm{H}_{2} \mathrm{O}, 0.01 \mathrm{~g}$ of $\mathrm{CaCl}_{2}, 0.005 \mathrm{~g}$ of $\mathrm{FeSO}_{4}, 0.002 \mathrm{~g}$ of $\mathrm{MnCl}_{2}, 2 \mathrm{ml}$ of glycerol, $15 \mathrm{~g}$ of agar, $\mathrm{pH} 7.0$ ) at $30^{\circ} \mathrm{C}$, while E. coli strains were cultured in $\mathrm{LB}$ medium at $37^{\circ} \mathrm{C}$. Rifampicin $(50 \mu \mathrm{g} / \mathrm{ml})$, streptomycin $(50 \mu \mathrm{g} / \mathrm{ml})$, kanamycin $(50 \mu \mathrm{g} / \mathrm{ml})$, and ampicillin $(100 \mu \mathrm{g} / \mathrm{ml})$, all purchased from Sigma, were used when appropriate.

Biochemical reagents, primers, and other materials.

Restriction enzymes SpeI, BamHI, HindIII, EcoRI, D2000 DNA ladder marker, PrimerSTARTM HS DNA polymerase, Taq DNA polymerase, T4 DNA ligase, Star Prep plasmid miniprep kit, Universal DNA purification kit, DNA fragment purification kit, PrimeScript RT master mix (for real time) and SYBR Premix Ex Taq II (Tli RNaseH Plus) were purchased from TaKaRa. SV total RNA isolation system was purchased from Promega. Primer synthesis and sequencing were performed by Invitrogen. Primer sequences are shown in Table 2.

\section{Gene knockout and complementation of IHF-encoding genes in $D$. zeae.}

Deletion mutants $\triangle i h f A$ and $\triangle i h f B$ were generated from the wild-type $D$. zeae strain EC1 by homologous recombination (Chen et al. 2014). Briefly, left and right homologous arms of ihfA were amplified by PCR, using genomic DNA from $D$. zeae EC1 as template and primer sets ihfA-U-F/ihfAU-R and ihfA-D-F/ihfA-D-R, respectively. The two amplified

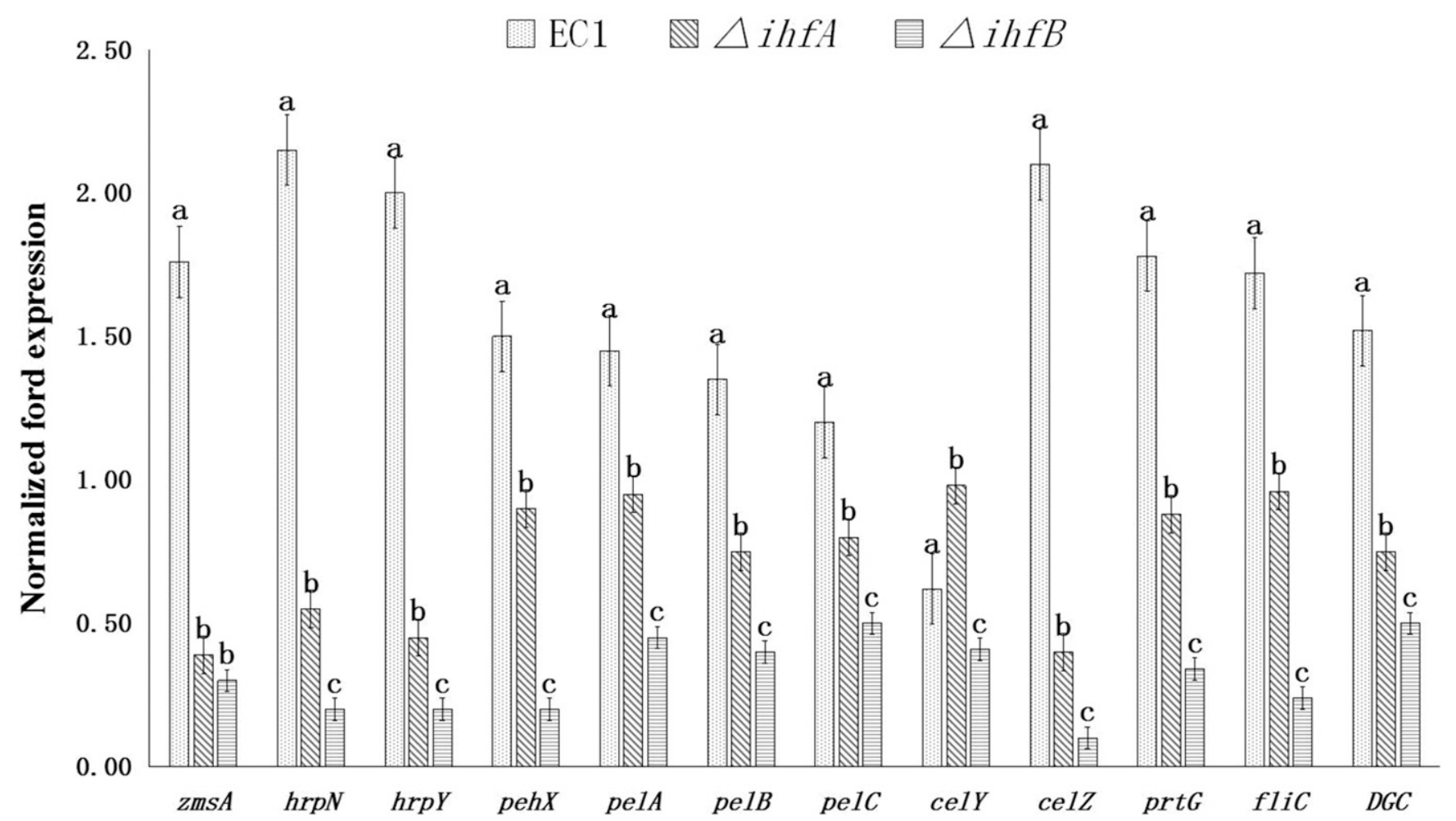

Fig. 7. Relative expression of genes associated with the virulence of Dickeya zeae wild-type strain EC1, $\Delta i h f A$, and $\triangle i h f B$ by quantitative reverse-transcription polymerase chain reaction at $24 \mathrm{~h}$ of growth. Gene of $16 \mathrm{~S}$ rDNA was used as an endogenous control to normalize gene expression data. Target genes were $z m s A$ (encodes a novel multimodular polyketide synthase for zeamine toxin), Hrp system ( $\mathrm{rrpN}$ and $\mathrm{hrp} Y$ ), pectate lyase genes (pelA, pelB, pelC), polygalacturonases ( $p e h X$ ), celY, and celZ (cellulase), prtG (serralysin G), fliC (a regulatory gene in the flagellum system), and $D G C$ (diguanylate cyclase). The values are means of three replicates and the error bars are standard deviation. 
fragments, which flanked ihfA, were fused together by PCR, using primers ihfA-U-F and ihfA-D-R. Following digestion with SpeI and BamHI, the fusion fragments were purified and were ligated into suicide vector pKNG101, to obtain recombinant plasmid pKNG- $\Delta i h f A$. The recombinant plasmid was then transformed into E. coli $\mathrm{K} 12 \mathrm{CC} 118$ and the transformed bacteria were grown on LB plates with streptomycin $(50 \mu \mathrm{g} / \mathrm{ml})$ at $37^{\circ} \mathrm{C}$ for $24 \mathrm{~h}$. Positive clones were detected by PCR using primers pKNG101-F/R and were verified by sequencing. The recombinant $E$. coli strain carrying plasmid pKNG- $\Delta i h f A$ and helper plasmid pRK2013 and wild-type strain EC1 were separately cultured overnight and were then mixed together for approximately $10 \mathrm{~h}$. During mixed culture, helper plasmid pRK2013 facilitated the transfer of the recombinant plasmid into the receptor $D$. zeae strain (triparental mating). As the recombinant plasmid contained sequences flanking the target gene that were homologous to the sequences in the $D$. zeae EC1 strain, homologous double-crossover recombination by the suicide vector resulted in deletion of the target gene. PCR analysis was used to confirm the deletion of $i h f A$ in the $\triangle i h f A$ mutant strain. A $\triangle i h f B$ mutant strain was constructed using the same method.

For complementation of $\triangle i h f A$ and $\triangle i h f B$, the promoter and coding sequences of the ihfA and $i h f B$ genes were amplified from $D$. zeae $\mathrm{EC} 1$ genomic DNA. The resulting amplicons were ligated into vector pBBR1MCS4. The recombinant plasmids, designated pBBR1-ihfA and pBBR1-ihfB, were transformed into $E$. coli $\mathrm{DH} 5 \alpha$. The resulting transformants were selected on LB plates containing ampicillin and streptomycin and were confirmed by PCR. Triparental mating was then performed
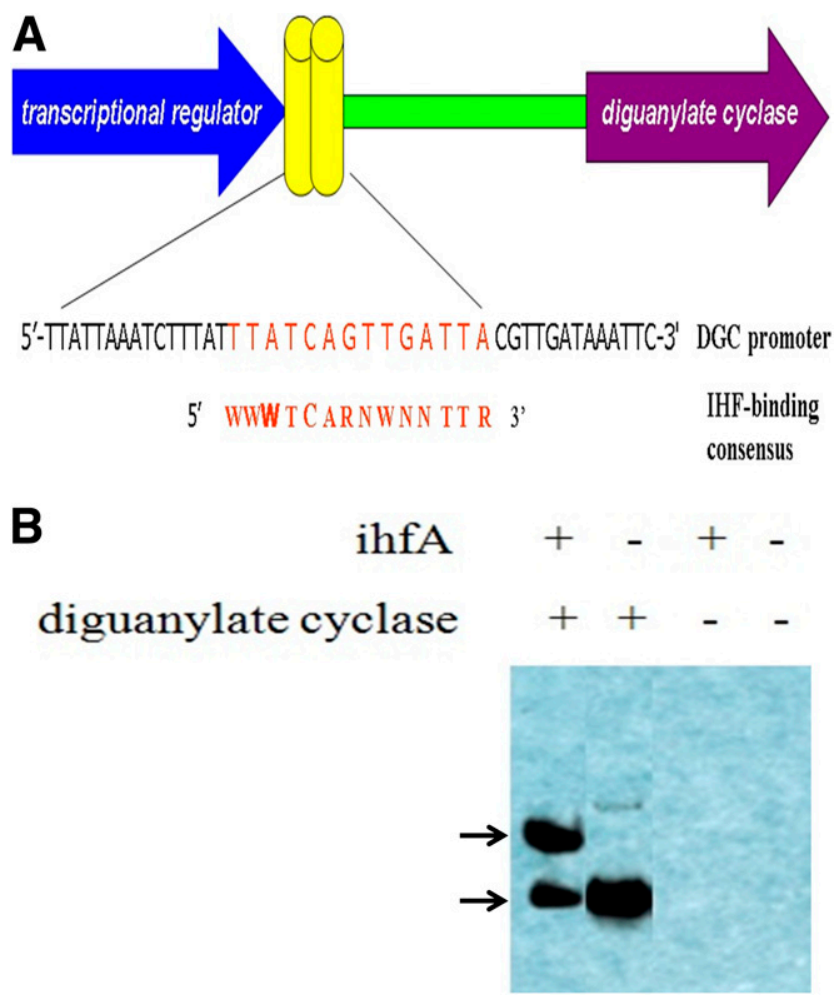

Fig. 8. Promoter binding region of ihfA protein to target gene $D G C$ (diguanylate cyclase) and electrophoretic mobility shift assay. A, Schematic of the intergenic region between transcriptional regulator and DGC in which the integration host factor (IHF) binding-site position is represented with a barrel. The alignment of the DGC IHF binding site with the consensus IHF binding site (Arvizu-Gómez et al. 2011) is also shown. W, A or T; R, A or G; N, any base. B, Electrophoretic mobility shift assay for testing the binding of ihfA protein to DGC promoter. Arrows indicate the free probe (the bottom bands) and the protein-DNA complex (the top band). between the recombinant plasmid, the mutant strain, and the pRK2013 helper plasmid, and the candidate complementation strains were screened using antibiotic selection. The resulting complementation strains, R- $\Delta i h f A$ and R- $\Delta i h f B$, were confirmed by plasmid extraction, double digestion of the isolated plasmid, and sequencing.

\section{Bacterial growth curve.}

To examine the growth of bacterial strains, cells from overnight cultures of the tested strains were harvested and were inoculated into fresh LB broth. The strains were then cultured at $30^{\circ} \mathrm{C}$ with shaking at $200 \mathrm{rpm}$. Every $2 \mathrm{~h}, 2-\mathrm{ml}$ volumes of each culture were collected to measure the optical density at $600 \mathrm{~nm}$ $\left(\mathrm{OD}_{600}\right)$. Three replicates were performed for each strain, and bacterial growth curves were plotted based on the average values.

\section{Motility and biofilm-formation assays.}

Determination of cell motility for each strain was conducted by measuring the diameters of the colonies on plates, as described previously (Shen et al. 2001; Yap et al. 2005). Briefly, all strains were cultured in $\mathrm{MM}$ overnight to achieve an $\mathrm{OD}_{600}=1.5$. Aliquots $(2 \mu \mathrm{l})$ of bacterial suspensions were then inoculated onto the surfaces of agar plates ( $10 \mathrm{~g}$ of tryptone, $5 \mathrm{~g}$ of $\mathrm{NaCl}$, and $2.5 \mathrm{~g}$ of agar per liter) and were incubated at $30^{\circ} \mathrm{C}$ for $24 \mathrm{~h}$. Each assay was repeated three times in triplicate.

The ability of the strains to form a biofilm was examined as described previously (Shen et al. 2001). A 10- $\mu$ l aliquot of bacterial cell culture $\left(\mathrm{OD}_{600}=0.5\right)$ was inoculated into tubes containing SONG medium (per liter: $20 \mathrm{~g}$ of tryptone, $5 \mathrm{~g}$ of yeast extract, $5 \mathrm{~g}$ of $\mathrm{NaCl}, 2.4 \mathrm{~g}$ of $\mathrm{MgSO}_{4} \cdot 7 \mathrm{H}_{2} \mathrm{O}, 0.186 \mathrm{~g}$ of $\mathrm{KCl}$, $50 \mathrm{ml}$ of $40 \%$ glycerin) and was incubated for $72 \mathrm{~h}$ at $28^{\circ} \mathrm{C}$.

\section{Examination of extracellular enzyme and toxin production.}

Bacterial protease, pectinase, and cellulase production was measured using protease, pectinase, and cellulase test plates,

Table 1. Bacterial strains and plasmids

\begin{tabular}{|c|c|c|}
\hline $\begin{array}{l}\text { Strains and } \\
\text { plasmids }\end{array}$ & Relevant characteristics $^{\mathbf{a}}$ & Origin \\
\hline \multicolumn{3}{|l|}{ Dickeya zeae } \\
\hline $\mathrm{EC} 1$ & Wild type, Rif $^{R}$ & $\begin{array}{l}\text { Lab } \\
\text { collection }\end{array}$ \\
\hline$\triangle i h f A$ & ihfA knockout mutant of EC1 & This study \\
\hline $\mathrm{R}-\Delta i h f A$ & Complementation strain of $\Delta i h f A$ & This study \\
\hline$\Delta i h f B$ & ihfB knockout mutant of EC1 & This study \\
\hline $\mathrm{R}-\Delta i h f B$ & Complementation strain of $\Delta i h f B$ & This study \\
\hline \multicolumn{3}{|l|}{ Escherichia coli } \\
\hline $\mathrm{K} 12 \mathrm{CC} 118$ & gyrA, recA, $\lambda$ pir & $\begin{array}{l}\text { Lab } \\
\text { collection }\end{array}$ \\
\hline DH5 $\alpha$ & $\begin{array}{l}\text { deoR, recA, endA, hsdR, supE, thi, } \\
\text { gyrA, relA }\end{array}$ & $\begin{array}{l}\text { Lab } \\
\text { collection }\end{array}$ \\
\hline \multicolumn{3}{|l|}{ Plasmids } \\
\hline pKNG101 & $\begin{array}{l}\mathrm{Sm}^{\mathrm{R}}, \mathrm{SacB}, \operatorname{mobRK} 2, \text { oriR6K (pir- } \\
\text { minus) }\end{array}$ & $\begin{array}{l}\text { Lab } \\
\text { collection }\end{array}$ \\
\hline pBBR1MCS4 & $\mathrm{Amp}^{\mathrm{R}}, \mathrm{Mob}^{+}, \mathrm{Tra}^{-}$, Cosmetic & $\begin{array}{l}\text { Lab } \\
\text { collection }\end{array}$ \\
\hline pRK2013 & $\begin{array}{l}\mathrm{Tra}^{+}, \mathrm{Mob}^{-}, \text {ColE1-replicon, } \mathrm{Kan}^{\mathrm{R}} \text {, } \\
\mathrm{Sp}^{\mathrm{R}}\end{array}$ & $\begin{array}{l}\text { Lab } \\
\text { collection }\end{array}$ \\
\hline pKNG- $\Delta i h f A$ & $\begin{array}{l}\text { ihfA knockout fragment ligated on } \\
\text { pKNG101 }\end{array}$ & This study \\
\hline pBBR1-ihfA & $\begin{array}{l}\text { ihf } A \text { complementation fragment ligated } \\
\text { on pBBR1MCS } 4\end{array}$ & This study \\
\hline pKNG- $\Delta i h f B$ & $\begin{array}{l}\text { ihfB knockout fragment ligated on } \\
\text { pKNG101 }\end{array}$ & This study \\
\hline pBBR1-ihfB & $\begin{array}{l}\text { ihfB complementation fragment ligated } \\
\text { on pBBR1MCS4 }\end{array}$ & This study \\
\hline
\end{tabular}


respectively, as described by Chatterjee et al. (1995). Aliquots of overnight cultures grown in MM were inoculated onto test plates and were further cultivated at $30^{\circ} \mathrm{C}$ for $24 \mathrm{~h}$. Each assay was repeated three times in triplicate. The protease test plates were observed directly, while the pectinase test plates were immersed in 1-mol/liter $\mathrm{HCl}$ to allow observation of the transparent zone. The cellulase test plates were stained with $0.1 \%$ (wt/vol) Congo red for $30 \mathrm{~min}$ and were then washed twice with $1 \mathrm{M} \mathrm{NaCl}$ for 15 min each time.

$D$. zeae produces a toxin that demonstrates bactericidal activity against $E$. coli. LB agar plates spread with a 1 in 10 dilution of an overnight culture of $E$. coli $\mathrm{DH} 5 \alpha$ were used for the toxin assay (Zhou et al. 2011). Aliquots of each of the test bacterial cultures were then spotted onto the plates. Bacterial inhibition was observed following culture at $30^{\circ} \mathrm{C}$ for $24 \mathrm{~h}$. Each assay was repeated three times in triplicate.

\section{Rice seed germination assay.}

A rice seed germination assay was conducted as described by Zhou et al. (2011). Briefly, 50 healthy rice seeds were immersed in $25 \mathrm{ml}$ of bacterial suspension for $5 \mathrm{~h}$ and were then washed three times with sterile water. The cleaned seeds were placed on moistened filter paper in a petri dish and were then incubated at $30^{\circ} \mathrm{C}$ with a 16-h light and 8-h dark cycle. LB broth was used as a control. The lengths of the root and bud of the germinated seeds were measured following 4 days of incubation.

\section{Potato tubes soft rot assay.}

A potato tuber soft rot assay was carried out as described previously (Zhou et al. 2011). Healthy potato tubers were washed and were sliced into pieces with a thickness of $5 \mathrm{~mm}$. The surface of each slice was air dried on an ultra-clean bench and was then exposed to ultraviolet light for $15 \mathrm{~min}$. Each slice was then placed in a petri dish lined with filter paper moistened with sterilized water. The surface of each slice was pricked with a sterilized needle and $2-\mu \mathrm{l}$ aliquots of the bacterial suspensions (strains were cultured in $\mathrm{LB}$ medium to $\mathrm{OD}_{600}=0.5$ ) were inoculated into the holes made by the needle. LB broth was used as a negative control. The inoculated potato slices were then incubated at $30^{\circ} \mathrm{C}$ for $24 \mathrm{~h}$. Each assay was repeated three times in triplicate. Potato slices were monitored regularly for the appearance of soft rot symptoms.

\section{Assays for HR on tobacco leaves and virulence in rice plants.}

Wild-type D. zeae strain EC1 along with the knockout mutants and complementation strains were individually inoculated

Table 2. Primers used in this study ${ }^{\mathrm{a}}$

\begin{tabular}{|c|c|c|c|}
\hline Primer & Sequences $\left(5^{\prime}\right.$ to $\left.3^{\prime}\right)$ & $\operatorname{Size}(b p)$ & Applications \\
\hline ihfA-U-F & CGGGATCCGTGTTTGAGAGCGGTTTACG & 690 & Fragment flanking the left of $i h f A$ gene \\
\hline ihfA-U-R & CAGGACTCTTTGGGTGACGCCATAGGTTAATCCCTCAAGG & & \\
\hline ihfA-D-F & CCTTGAGGGATTAACCTATGGCGTCACCCAAAGAGTCCTG & 432 & Fragment flanking the right of $i h f A$ gene \\
\hline ihfA-D-R & CGGACTAGTTATGAGCGTGCCTTTCCAGC & & \\
\hline ihfA-F & CCC $\overline{A A G C T T G G A A A T T G C C G C T A C C G T T G ~}$ & 377 & Complementation fragment of ihfA \\
\hline ihfA-R & CGGGATCCATCAGGACTCTTTGGGTGAC & & \\
\hline ihfB-U-F & CGGGATCC CGTAGTGGAAGTTATGGTTC & 771 & Fragment flanking the left of $i h f B$ gene \\
\hline ihfB-U-R & CAGGCGTTATGACTGACTAAGTGGTCAGTAAATACCACG & & \\
\hline ihfB-D-F & CGTGGTATTTACTGACCACTTAGTCAGTCATAACGCCTG & 472 & Fragment flanking the right of $i h f B$ gene \\
\hline ihfB-D-R & CGGACTAGTGGACTACAACAGGAACAGGT & & \\
\hline ihfB-F & CCC $\overline{\text { AAGCTTAAGGCGAGTAATGACGGTGG }}$ & 443 & Complementation fragment of ihfB \\
\hline ihfB-R & CGGGATCCGACAAAAAATAGCACCCGGC & & \\
\hline ihfA-CX-F & CGGTGAGCAGGCATTGATTC & 1399 & For $i h f A$ deletion sequencing \\
\hline ihfA-CX-R & AGCACCTTAAACGGCGACAG & & \\
\hline ihfB-CX-F & CGAAGAAGGCGTTGAAGGTC & 1482 & For $i h f B$ deletion sequencing \\
\hline ihfB-CX-R & CGTTCTGACCATTCTCCAGC & & \\
\hline $16 \mathrm{~S}-\mathrm{qF}$ & GCAACGCGAAGAACCTTACCT & 94 & For qRT-PCR \\
\hline $16 \mathrm{~S}-\mathrm{qR}$ & GCCATGCAGCACCTGTCT & & \\
\hline $\mathrm{zmsA}-\mathrm{qF}$ & CCGGGCTCGTTTGATTTCTTTG & 81 & For qRT-PCR \\
\hline zmsA-qR & CGCTTTGTCTGAACGCAACATC & & \\
\hline hrpN-qF & AGGGCGATCAGAAGTCTTTGC & 119 & For qRT-PCR \\
\hline hrpN-qR & CGCCTGGCCTAAACCATTACC & & \\
\hline hrpY-qF & ATCGTGTTTGCGGATTGTC & 70 & For qRT-PCR \\
\hline hrpY-qR & TGCTCGCGTGTGGTCAAC & & \\
\hline pelA-qF & CCACCAAAGATGGCGAAACCT & 86 & For qRT-PCR \\
\hline pelA-qR & GCTGTTGGAGATGGTCACGTAGT & & \\
\hline pelB-qF & CGTCACCATCTCCTACAACTACATC & 78 & For qRT-PCR \\
\hline pelB-qR & TCAGCGGTGTCAGAAGAACTG & & \\
\hline pelC-qF & CAACCGCTATAACGACGTGAAC & 99 & For qRT-PCR \\
\hline pelC-qR & AGACCGGAACTGGTGACATTG & & \\
\hline celY-qF & CGTCGGATGGTGATGTACTGAT & 90 & For qRT-PCR \\
\hline celY-qR & TGACCGATGACCGCTTTCTG & & \\
\hline celZ-qF & AGCGATGGCTGAATCTGAATCC & 100 & For qRT-PCR \\
\hline celZ-qR & GCACTGTTGCTGTCAATGTCG & & \\
\hline prtG-qF & TGGGATGGTCAAGCGAATCAG & 93 & For qRT-PCR \\
\hline prtG-qR & CAACGCCGTACCGACAATCTTC & & \\
\hline pehX-qF & CGGTCGTACTGGGTAGCCATAC & 78 & For qRT-PCR \\
\hline pehX -qR & GCAGGCCGATGTCGCTTT & & \\
\hline fliC-qF & GGTGCAGACTGCTGAAGGT & 90 & For qRT-PCR \\
\hline fliC-qR & CGGTCAAGAGAACCGTTGGTATC & 90 & For qRT-PCR \\
\hline DGC-qF & GAAGATTCGTCAGGCCGTTC & 90 & For qRT-PCR \\
\hline DGC-qR & ATTAGATTCCGCAACACCGC & & \\
\hline MCS-F & TCTTCGCTATTACGCCAGCT & & Universal primer of $\mathrm{pBBR} 1 \mathrm{MCS} 4$ \\
\hline MCS-R & GGCTCGTATGTTGTGTGGAA & & \\
\hline
\end{tabular}

\footnotetext{
${ }^{\mathrm{a}}$ Underlined sequences indicate the restriction enzyme cleavage sites. qRT-PCR $=$ quantitative reverse-transcription polymerase chain reaction.
} 
into LB broth supplemented with the appropriate antibiotics. Bacterial cells were collected by centrifugation at $6,000 \mathrm{rpm}$ for $10 \mathrm{~min}$ and were resuspended in sterile water to an $\mathrm{OD}_{600}=$ 0.5 . The bacterial suspensions were injected into tobacco leaves and onto the base of rice seedlings (three pots per treatment, three seedlings per pot), using a sterilized needle-free injector. LB broth was used as a negative control. Symptoms of HR were observed on the tobacco leaves within $24 \mathrm{~h}$ of inoculation. Rice seedlings were monitored regularly for symptom development.

\section{Expression analysis of some important virulent genes.}

To verify the genes regulated by IHF, the expression of several virulence genes was examined by qRT-PCR analysis. Total bacterial RNA was extracted using a SV total RNA isolation system kit, and the eluted RNA was DNase-treated using Turbo DNA-free, according to the manufacturer's instructions (Promega). The quality and quantity of the total RNA were assessed using agarose gel electrophoresis and spectrophotometer, respectively. Reverse transcription for cDNA synthesis was performed using PrimeScript RT master mix (TaKaRa), and $100 \mathrm{ng}$ of cDNA was used for qRT-PCR analysis using a SYBR Premix Ex Taq II (Tli RNaseH Plus) kit (TaKaRa). The 16S rRNA gene was used as an endogenous control to normalize gene-expression data. Target genes zmsA (encodes a novel multimodular polyketide synthase for zeamine toxin), $h r p N$ and $h r p Y$ (Hrp system), pectate lyase genes (pelA, pelB, and pelC), polygalacturonases (pehX), cellulase genes (celY and celZ)), prtG (Serralysin G), fliC(a regulatory gene in flagellum system), and $D G C$ were analyzed. Relative expression levels of the target genes were calculated using the $2^{-\Delta \Delta \mathrm{Ct}}$ method (Livak et al. 2001), with the following formulas.

Relative expression levels of target gene $=2^{-\Delta \Delta \mathrm{Ct}}$

$$
-\Delta \Delta \mathrm{Ct}=-\left(\Delta \mathrm{Ct}_{\mathrm{q}}-\Delta \mathrm{Ct}_{\mathrm{cb}}\right)
$$

where $\mathrm{Ct}$ is the threshold cycle, $\mathrm{q}$ is the treated sample, and $\mathrm{cb}$ is the control sample.

\section{Binding of IhfA to the DGC promoter.}

Expression and purification of IhfA. An E. coli codonoptimized synthetic $D$. zeae ihfA gene for protein expression was purchased from Invitrogen. Forward (5'-CATATGCAC CATCACCATCACCAT- $\left.3^{\prime}\right)$ and reverse (5'-AAGCTTTCA TTAACTTTCTTTCGGGC-3') primers were then designed to amplify ihfA. The amplified ihfA gene was cloned into protein expression vector pET30a at the NdeI and HindIII restriction sites, generating plasmid pET30a-ihfA. The recombinant plasmid was then transformed into E. coli BL21(DE3). The resulting transformant strain was cultured and protein expression was induced with isopropyl $\beta$-D-thiogalactopyranoside. Expressed protein IhfA was then purified from E. coli BL21 (DE3) cells by affinity chromatography (Ni-IDA).

EMSA. The synthesis and labeling of a DGC probe with biotin were performed by Invitrogen. The probe sequence (TAGTTATTAAATCTTTATTTATCAGTTGATTACGTTGATA AATTCGGTCC) was derived from the DGC promoter region. The EMSA binding reaction mixtures $(10 \mu \mathrm{l})$ contained EMSA/gel-shift binding buffer (5x), purified D. zeae IhfA, and DGC probe. Control reactions without one or both IhfA and DGC probe were included. Reactions were incubated at room temperature for $20 \mathrm{~min}$ and were then loaded into a $6 \%$ native polyacrylamide gel in $0.5 \times$ Tris-borate-EDTA buffer. Following electrophoresis, the resolved proteins with bound probes were transferred to a positively charged nylon membrane. After UV crosslinking, chemiluminescence detection was carried out.

\section{ACKNOWLEDGMENTS}

We thank T. Sheen from Liwen Bianji, Edanz Editing China for editing the English text of a draft of this manuscript.

\section{LITERATURE CITED}

Arfin, S. M., Long, A. D., Ito, E. T., Tolleri, L., Riehle, M. M., Paegle, E. S., and Hatfield, G. W. 2000. Global gene expression profiling in Escherichia coli K12. The effects of integration host factor. J. Biol. Chem. 275:29672-29684.

Arvizu-Gómez, J. L., Hernández-Morales, A., Pastor-Palacios, G., Brieba, L. G., and Álvarez-Morales, A. 2011. Integration Host Factor (IHF) binds to the promoter region of the phtD operon involved in phaseolotoxin synthesis in P. syringae pv. phaseolicola NPS3121. BMC Microbiol. 11:90.

Chatterjee, A., Cui, Y., and Chatterjee, A. K. 2002. Regulation of Erwinia carotovora $\mathrm{hrpL}_{E c c}\left(\right.$ sigma- $\left.\mathrm{L}_{\mathrm{Ecc}}\right)$, which encodes an extracytoplasmic function subfamily of sigma factor required for expression of the HRP regulon. Mol. Plant-Microbe Interact. 15:971-980.

Chatterjee, A., Cui, Y., Liu, Y., Dumenyo, C. K., and Chatterjee, A. K. 1995. Inactivation of rsmA leads to overproduction of extracellular pectinases, cellulases, and proteases in Erwinia carotovora subsp. carotovora in the absence of the starvation/cell density-sensing signal, N-(3-oxohexanoyl)-L-homoserine lactone. Appl. Environ. Microbiol. 61:1959-1967.

Chatterjee, S., Killiny, N., Almeida, R. P. P., and Lindow, S. E. 2010. Role of cyclic di-GMP in Xylella fastidiosa biofilm formation, plant virulence, and insect transmission. Mol. Plant-Microbe Interact. 23:1356-1363.

Chen, X. F., Wei, C. D., Zhang, Q., and Liu, Q. G. 2014. Functional analysis of HrpX/HrpY in Dickeya zeae virulence. Scientia Agricultura Sinica 47: 675-684.

Cheng, Y., Liu, X., An, S., Chang, C., Zou, Y., Huang, L., Zhong, J., Liu, Q., Jiang, Z., Zhou, J., and Zhang, L. H. 2013. A nonribosomal peptide synthase containing a stand-alone condensation domain is essential for phytotoxin zeamine biosynthesis. Mol. Plant-Microbe Interact. 26 1294-1301.

Chin, K. H., Lee, Y. C., Tu, Z. L., Chen, C. H., Tseng, Y. H., Yang, J. M., Ryan, R. P., McCarthy, Y., Dow, J. M., Wang, A. H., and Chou, S. H 2010. The cAMP receptor-like protein CLP is a novel c-di-GMP receptor linking cell-cell signaling to virulence gene expression in Xanthomonas campestris. J. Mol. Biol. 396:646-662.

Chua, K. L., Chan, Y. Y., and Gan, Y. H. 2003. Flagella are virulence determinants of Burkholderia pseudomallei. Infect. Immun. 71:1622-1629.

Dahlstrom, K. M., Giglio, K. M., Sondermann, H., and O'Toole, G. A. 2016. The inhibitory site of a diguanylate cyclase is a necessary element for interaction and signaling with an effector protein. J. Bacteriol. 198: 1595-1603

Deane, J. E., Abrusci, P., Johnson, S., and Lea, S. M. 2010. Timing is everything: The regulation of type III secretion. Cell. Mol. Life Sci. 67: 1065-1075.

Dorman, C. J. 2009. Nucleoid-associated proteins and bacterial physiology. Adv. Appl. Microbiol. 67:47-64.

Dow, J. M., Crossman, L., Findlay, K., He, Y. Q., Feng, J. X., and Tang, J. L. 2003. Biofilm dispersal in Xanthomonas campestris is controlled by cellcell signaling and is required for full virulence to plants. Proc. Natl. Acad. Sci. U.S.A. 100:10995-11000.

Edmunds, A. C., Castiblanco, L. F., Sundin, G. W., and Waters, C. M. 2013. Cyclic Di-GMP modulates the disease progression of Erwinia amylovora. J. Bacteriol. 195:2155-2165.

Eriksson, A. R., Andersson, R. A., Pirhonen, M., and Palva, E. T. 1998. Twocomponent regulators involved in the global control of virulence in Erwinia carotovora subsp. carotovora. Mol. Plant-Microbe Interact. 11:743-752.

Haluzi, H., Goitein, D., Koby, S., Mendelson, I., Teff, D., Mengeritsky, G., Giladi, H., and Oppenheim, A. B. 1991. Genes coding for integration host factor are conserved in gram-negative bacteria. J. Bacteriol. 173:6297-6299.

Hirano, T. 2006. At the heart of the chromosome: SMC proteins in action. Nat. Rev. Mol. Cell Biol. 7:311-322.

Hussain, M. B. B. M., Zhang, H. B., Xu, J. L., Liu, Q., Jiang, Z., and Zhang, L. H. 2008. The acyl-homoserine lactone-type quorum-sensing system modulates cell motility and virulence of Erwinia chrysanthemi pv. zeae J. Bacteriol. 190:1045-1053.

Jenal, U., Reinders, A., and Lori, C. 2017. Cyclic di-GMP: Second messenger extraordinaire. Nat. Rev. Microbiol. 15:271-284.

Kim, T. J., Young, B. M., and Young, G. M. 2008. Effect of flagellar mutations on Yersinia enterocolitica biofilm formation. Appl. Environ. Microbiol. 74:5466-5474. 
Lara-Tejero, M., Kato, J., Wagner, S., Liu, X., and Galán, J. E. 2011. A sorting platform determines the order of protein secretion in bacterial type III systems. Science 331:1188-1191.

Lee, J. H., and Zhao, Y. 2016. Integration host factor is required for RpoNDependent $h r p L$ gene expression and controls motility by positively regulating rsmB sRNA in Erwinia amylovora. Phytopathology 106: 29-36.

Lee, J. H., and Zhao, Y. 2018. Integration of multiple stimuli-sensing systems to regulate HrpS and type III secretion system in Erwinia amylovora. Mol. Genet. Genomics 293:187-196.

Liang, Y., Gao, H., Chen, J., Dong, Y., Wu, L., He, Z., Liu, X., Qiu, G., and Zhou, J. 2010. Pellicle formation in Shewanella oneidensis. BMC Microbiol. 10:291.

Liu, Q. G., Yuan, Y., Liang, J. J., Wei, C. D., Zhang, Q., and Li, H. P. 2015. Physiological and biochemical characteristics and multilocus sequence analysis of banana soft rot bacteria in China. J. Plant Pathol. 97:69-75.

Liu, Q. G., Zhang, Q., and Wei, C. D. 2013. Advances in research of rice bacterial foot rot. Scientia Agricultura Sinica 46:2923-2931.

Livak, K. J., and Schmittgen, T. D. 2001. Analysis of relative gene expression data using real-time quantitative PCR and the $2^{-\Delta \Delta C t}$ method. Methods 25:402-408.

Mangan, M. W., Lucchini, S., Danino, V., Cróinín, T. O., Hinton, J. C., and Dorman, C. J. 2006. The integration host factor (IHF) integrates stationary-phase and virulence gene expression in Salmonella enterica serovar Typhimurium. Mol. Microbiol. 59:1831-1847.

Matsumoto, H., Jitareerat, P., Baba, Y., and Tsuyumu, S. 2003. Comparative study of regulatory mechanisms for pectinase production by Erwinia carotovora subsp. carotovora and Erwinia chrysanthemi. Mol. PlantMicrobe Interact. 16:226-237.

Merighi, M., Majerczak, D. R., Zianni, M., Tessanne, K., and Coplin, D. L. 2006. Molecular characterization of Pantoea stewartii subsp. stewartii HrpY, a conserved response regulator of the Hrp type III secretion system, and its interaction with the hrpS promoter. J. Bacteriol. 188: 5089-5100.

Miller, H. I., and Friedman, D. I. 1980. An E. coli gene product required for $\lambda$ site-specific recombination. Cell 20:711-719.

Muñoz, A., Valls, M., and de Lorenzo, V. 2010. Extreme DNA Bending: Molecular Basis of the Regulatory Breadth of IHF. Pages 365-393 in: Bacterial Chromatin. R. T. Dame and C. J. Dorman, eds. Springer, Heidelberg.

Palacios, S., and Escalante-Semerena, J. C. 2000. prpR, ntrA, and ihf functions are required for expression of the prpBCDE operon, encoding enzymes that catabolize propionate in Salmonella enterica serovar typhimurium LT2. J. Bacteriol. 182:905-910.

Parkinson, N., Stead, D., Bew, J., Heeney, J., Tsror Lahkim, L., and Elphinstone, J. 2009. Dickeya species relatedness and clade structure determined by comparison of recA sequences. Int. J. Syst. Evol. Microbiol. 59:2388-2393.
Porter, M. E., and Dorman, C. J. 1997. Positive regulation of Shigella flexneri virulence genes by integration host factor. J. Bacteriol. 179: 6537-6550.

Reverchon, S., Muskhelisvili, G., and Nasser, W. 2016. Virulence program of a bacterial plant pathogen: The Dickeya model. Prog. Mol. Biol Transl. Sci. 142:51-92.

Römling, U., Galperin, M. Y., and Gomelsky, M. 2013. Cyclic di-GMP: The first 25 years of a universal bacterial second messenger. Microbiol. Mol. Biol. Rev. 77:1-52.

Ryan, R. P. 2013. Cyclic di-GMP signalling and the regulation of bacterial virulence. Microbiology 159:1286-1297.

Schirmer, T., and Jenal, U. 2009. Structural and mechanistic determinants of c-di-GMP signalling. Nat. Rev. Microbiol. 7:724-735.

Shen, Y., Chern, M., Silva, F. G., and Ronald, P. 2001. Isolation of a Xanthomonas oryzae pv. oryzae flagellar operon region and molecular characterization of flhF. Mol. Plant-Microbe Interact. 14:204-213.

Sieira, R., Comerci, D. J., Pietrasanta, L. I., and Ugalde, R. A. 2004. Integration host factor is involved in transcriptional regulation of the Brucella abortus virB operon. Mol. Microbiol. 54:808-822.

Stonehouse, E., Kovacikova, G., Taylor, R. K., and Skorupski, K. 2008. Integration host factor positively regulates virulence gene expression in Vibrio cholerae. J. Bacteriol. 190:4736-4748.

Su, J. M., Zou, X., Huang, L. B., Bai, T. L., Liu, S., Yuan, M., Chou, S. H., He, Y. W., Wang, H. H., and He, J. 2016. DgcA, a diguanylate cyclase from Xanthomonas oryzae pv. oryzae regulates bacterial pathogenicity on rice. Nat. Sci. Rep. 6:25978.

Wagner, R. 2000. Regulation by transcription factors. Pages 193-260 in: Transcription Regulation in Prokaryotes. Oxford Press, Oxford.

Wei, Z., Kim, J. F., and Beer, S. V. 2000. Regulation of hrp genes and type III protein secretion in Erwinia amylovora by HrpX/HrpY, a novel twocomponent system, and HrpS. Mol. Plant-Microbe Interact. 13: 1251-1262.

Wu, J., Zhang, H. B., Xu, J. L., Cox, R. J., Simpson, T. J., and Zhang, L. H 2010. ${ }^{13} \mathrm{C}$ labeling reveals multiple amination reactions in the biosynthesis of a novel polyketide polyamine antibiotic zeamine from Dickeya zeae. Chem. Commun. (Camb.) 46:333-335.

Yap, M. N., Yang, C. H., Barak, J. D., Jahn, C. E., and Charkowski, A. O. 2005. The Erwinia chrysanthemi type III secretion system is required for multicellular behavior. J. Bacteriol. 187:639-648.

Yi, X., Yamazaki, A., Biddle, E., Zeng, Q., and Yang, C. H. 2010. Genetic analysis of two phosphodiesterases reveals cyclic diguanylate regulation of virulence factors in Dickeya dadantii. Mol. Microbiol. 77:787-800.

Zhang, Q., Yu, C. P., Wen, L. P., Liu, Q. G. 2018. Tat system is required for the virulence of Dickeya zeae on rice plants. J. Plant Pathol. 100: 409-418.

Zhou, J., Zhang, H., Wu, J., Liu, Q., Xi, P., Lee, J., Liao, J., Jiang, Z., and Zhang, L. H. 2011. A novel multidomain polyketide synthase is essential for zeamine production and the virulence of Dickeya zeae. Mol. PlantMicrobe Interact. 24:1156-1164. 